\title{
Effects of oestradiol-17 $\beta$ on peripheral plasma concentrations of LH and FSH in ovariectomized tammars (Macropus eugenii)
}

\author{
C. A. Horn, T. P. Fletcher and S. Carpenter* \\ Division of Wildlife and Rangelands Research, CSIRO, P.O. Box 84, Lyneham, A.C.T. 2602, and \\ *Division of Mathematics and Statistics, CSIRO, GPO Box 1965, Canberra City, A.C.T. 2601, \\ Australia
}

\begin{abstract}
Summary. Two experiments, each using 8 animals, were conducted in the non-breeding and breeding seasons, respectively, and each animal was injected with 4 different doses of oestradiol benzoate over 4 trials. The resulting physiological concentrations of plasma oestradiol caused depression of both LH and FSH values. The highest dose elicited a biphasic response in $\mathrm{LH}$ with a pulse-like surge at $24 \mathrm{~h}$ after injection. There was no significant difference between the response of either hormone at the two times of the year and it is concluded that, in tammars, there is no seasonal difference in the responsiveness of the hypothalamus/pituitary to the negative feedback effect of oestradiol.
\end{abstract}

\section{Introduction}

For much of the year the female tammar has an undeveloped or quiescent corpus luteum (CL) in one ovary, which is tonically suppressed by pituitary secretions (Tyndale-Biscoe, Hearn \& Renfree, 1974). Nevertheless, during quiescence the CL itself inhibits follicular growth and ovulation and, after reactivation, continues to do so for the first half of the ensuing oestrous cycle (Tyndale-Biscoe \& Hawkins, 1977). Since the later stages of follicular growth and ovulation are dependent on the pituitary gland (Hearn, 1974), it is likely that the CL inhibition is effected by a negative feedback to the hypothalamus or pituitary. Gonadotrophin concentrations in peripheral plasma are consistently low in intact females at all times of the year, except for a transient preovulatory surge of LH (Hearn, 1974; Sutherland, Evans \& Tyndale-Biscoe, 1980; Evans, Tyndale-Biscoe \& Sutherland, 1980), but after bilateral ovariectomy plasma concentrations of LH and FSH increase. In females ovariectomized and implanted with ovarian cortex in which luteal tissue subsequently developed, the plasma LH and FSH levels first increased and then reverted to basal values (Evans et al., 1980) or remained at basal values (Tyndale-Biscoe \& Hearn, 1981).

Both progesterone and oestradiol have been proposed as the agent of CL inhibition. Progesterone is the main steroid secreted by the CL (Renfree, Green \& Young, 1979) but the period when the CL exerts its strongest inhibition coincides with the lowest concentrations of progesterone in the circulation (Hinds \& Tyndale-Biscoe, 1982; Tyndale-Biscoe \& Hinds, 1984). Furthermore, after excision of the CL, treatment with progesterone did not prevent follicular growth or ovulation, whereas oestradiol alone or in combination with progesterone did do so (Evans et al., 1980; Renfree, Wallace \& Young, 1982). Oestradiol concentrations in peripheral plasma are generally very low or undetectable during seasonal quiescence $(<10 \mathrm{pg} / \mathrm{ml})$ (Flint \& Renfree, 1982) and during pregnancy and the oestrous cycle (Shaw \& Renfree, 1984). A transient peak $(16 \mathrm{pg} / \mathrm{ml})$ occurs early in these cycles with significant increases around the time of mating (21 $\mathrm{pg} / \mathrm{ml}$ ) (Shaw \& Renfree, 1984) and oestrus (12.7 pg/ml) (Harder, Hinds, Horn \& Tyndale-Biscoe, 1984). 
Oestradiol and oestrone have been measured in quiescent and active CL but luteal aromatase was undetectable (Renfree, Flint, Green \& Heap, 1984). Therefore, if oestradiol is the agent of follicular inhibition by the CL it is not clear how it is produced or how it would affect gonadotrophin concentrations.

The first purpose of this study was to determine whether oestradiol can exert an inhibitory effect on the pituitary when administered at physiological concentrations to ovariectomized females with high peripheral plasma levels of FSH and LH. The second purpose was to compare the response to the same treatment in females during the breeding season and during the non-breeding season to ascertain whether there was any change in hypothalamic or pituitary responsiveness to negative feedback at these two periods, as has been observed in the ewe (Legan \& Karsch, 1980) and has been postulated by Hearn, Short \& Baird (1977) as a possible factor in the seasonal breeding of the tammar.

\section{Materials and Methods}

Animals. The tammars came from a breeding colony in Canberra originally established with animals brought from Kangaroo Island, South Australia in 1974. Apart from the time of surgery and Day 1 of any trial, they were maintained in grassy outdoor pens and were provided with water and a pelletted mixture of lucerne and oats. All the animals were sexually mature adults aged more than 2 years with mean weights of $5 \mathrm{~kg}$ and $4.7 \mathrm{~kg}$ in Exps 1 and 2 respectively.

Two experiments were performed using two groups of 8 ovariectomized tammars, one in November-December during seasonal quiescence and the other in March-April during the breeding season. In Exp. 1, 2 of the animals had had their ovaries removed more than 12 months beforehand and the other 6 were ovariectomized 1 month before treatment. In Exp. 2 all 8 animals were ovariectomized 5 weeks before treatment began.

Steroids. Crystalline oestradiol-17ß,3-benzoate (Sigma, St Louis, MO, U.S.A.) was dissolved in olive oil at three concentrations which were based on a preliminary experiment by Evans (1978). At each treatment each animal was injected $\mathrm{i} . \mathrm{m}$. with $0.5 \mathrm{ml}$ of solution which delivered a total dose of $0,0 \cdot 5,2 \cdot 5$, or $12 \cdot 5 \mu \mathrm{g}$ oestradiol benzoate per animal.

Blood samples. During the time of blood sampling the animals were placed in hessian wheat sacks, in which they remain quiet, and samples of 3-4 ml blood were taken from a tail vein using an indwelling catheter (Surflo 20-gauge i.v. catheter) and heparinized syringe. The blood was kept on ice until the plasma was collected by centrifugation. The plasma was divided into aliquants and stored at $-20^{\circ} \mathrm{C}$ until assayed for LH, FSH and oestradiol.

Hormone assays. Plasma oestradiol, LH and FSH concentrations were measured by RIAs which have been validated for use with tammar plasma. Oestradiol was measured using the method described by Harder et al. (1984) using antiserum 6181 from Dr R. I. Cox, CSIRO, Sydney. The sensitivity was $2.5 \mathrm{pg} / \mathrm{ml}$ and the intra- and inter-assay coefficients of variation were $3 \%$ and $15 \%$ respectively. LH was measured by the method of Sutherland et al. (1980) using anti-ovine LH (GDN15) from Professor G. Niswender. The radioligand was NIAMDD-rat-LH I-6; the sensitivity was $0.3 \mathrm{ng} / \mathrm{ml}$ and the intra- and inter-assay coefficients of variation were $6.3 \%$ and $12.8 \%$ respectively. FSH was measured using the method of Evans et al. (1980) using anti-ovine FSH (H31) from Dr H. Papkoff and NIH-o-FSH-S13 as the reference standard instead of NIH-oFSH-S12. This standard improved the sensitivity of the assay from $50 \mathrm{ng} / \mathrm{ml}$ to $1 \cdot 2 \mathrm{ng} / \mathrm{ml}$. The intraand inter-assay coefficients of variation were $8.0 \%$ and $16.8 \%$ respectively.

Experimental design. The aim was to expose each animal sequentially to each of the 3 doses of oestradiol and the oil blank and determine the responses in LH and FSH. In each experiment 8 animals were randomized to receive each of the 4 doses over 4 trials, each 2 weeks apart. To test for 
any residual effects of the prior dose carrying over to the next trial the sequence of doses was balanced so that there were two occasions on which each dose was followed by each of the other doses at the next trial. Similar designs and their statistical analyses are described by John \& Quenouille (1977).

In Exp. 1 (November-December) blood was collected at ovariectomy (6 animals) and then 4 weeks later in reference to the time of injection of oestradiol or oil at $-96,0,2,4,6,9,12,24,96 \mathrm{~h}$ and at 10 days. The 10-day sample was also the $-96 \mathrm{~h}$ sample for the next trial. In Exp. 2 (MarchApril) additional samples were taken 18,30 and $48 \mathrm{~h}$ after injection.

Statistical analyses. For analysis the data for all 3 hormones were $\log _{\mathrm{e}}$ transformed. Analyses of variance were used to test the results from the changeover design for evidence of residual effects of the oestradiol injection. Further analyses of variance were used to test for significant differences (at $1 \%$ level) between animals, trials and doses of oestradiol. When there were comparable data in the two experiments, i.e. from $-2 \mathrm{~h}$ to $24 \mathrm{~h}$ after injection, the hormone responses to oestradiol were tested for differences between the breeding and non-breeding season, independent of animal differences. Responses at the various times relative to injection were treated separately in the analyses of variance.

\section{Results}

Each trial was separated by 14 days and the animals, with one exception, showed no residual dosage effect before the start of the next trial: in Exp. 2 one animal failed to regain preinjection concentrations of FSH after the second trial and the results of its remaining trials were deleted from analysis.

In both experiments the gonadotrophin concentrations increased after ovariectomy from basal to similar levels over the same time and these elevated values were regained by the end of the trials (Table 1). The pre-ovariectomy value for FSH in Exp. 1 was not taken.

Table 1. Summary of $\mathrm{LH}$ and FSH response (mean \pm s.e.m., $N=8$ ) after ovariectomy and injection with oestradiol benzoate of tammars in the non-breeding season (Exp. 1) and breeding season (Exp. 2)

\begin{tabular}{lrrrrr}
\hline & \multicolumn{2}{c}{ FSH (ng/ml) } & & \multicolumn{2}{c}{ LH (ng/ml) } \\
\cline { 2 - 3 } \cline { 5 - 6 } & \multicolumn{1}{c}{ Exp. 1 } & \multicolumn{1}{c}{ Exp. 2 } & & \multicolumn{1}{c}{ Exp. 1 } & Exp. 2 \\
\hline At ovariectomy & - & $2.0 \pm 0.9$ & & a $1.6 \pm 0.6$ & $1.8 \pm 0.6$ \\
At injection & $21.8 \pm 0.8$ & $20.6 \pm 0.6$ & & $8.8 \pm 1.8$ & $6.7 \pm 1.1$ \\
& a.c20.7 0.8 & & & a.c $7.8 \pm 2.2$ & \\
At maximum response & h9.7 0.7 & $6.9 \pm 1.2$ & & $1.6 \pm 0.6$ & $1.8 \pm 0.2$ \\
At + 14 days & $22.4 \pm 0.7$ & $19.9 \pm 0.4$ & & $10.3 \pm 1.8$ & $6.0 \pm 0.5$ \\
\hline
\end{tabular}

${ }^{a} \mathrm{~N}=6 ;{ }^{b} \mathrm{~N}=4 ;{ }^{c}$ ovariectomized at least 4 weeks earlier.

The pattern of response in all three hormones to the oestradiol doses was similar for each season (Text-figs $1 \& 2$ ) with no substantial differences between any of the corresponding 4 trials in Exps 1 or 2 .

\section{Oestradiol}

In both experiments injection of the highest dose of oestradiol resulted in significant $(P<0.01)$ increases in peripheral plasma oestradiol concentration at 4-24 h with a peak of $55-70 \mathrm{pg} / \mathrm{ml}$ at $12 \mathrm{~h}$. The level in control animals at $12 \mathrm{~h}$ was $5.4-9.9 \mathrm{pg} / \mathrm{ml}$. The intermediate dose caused smaller 

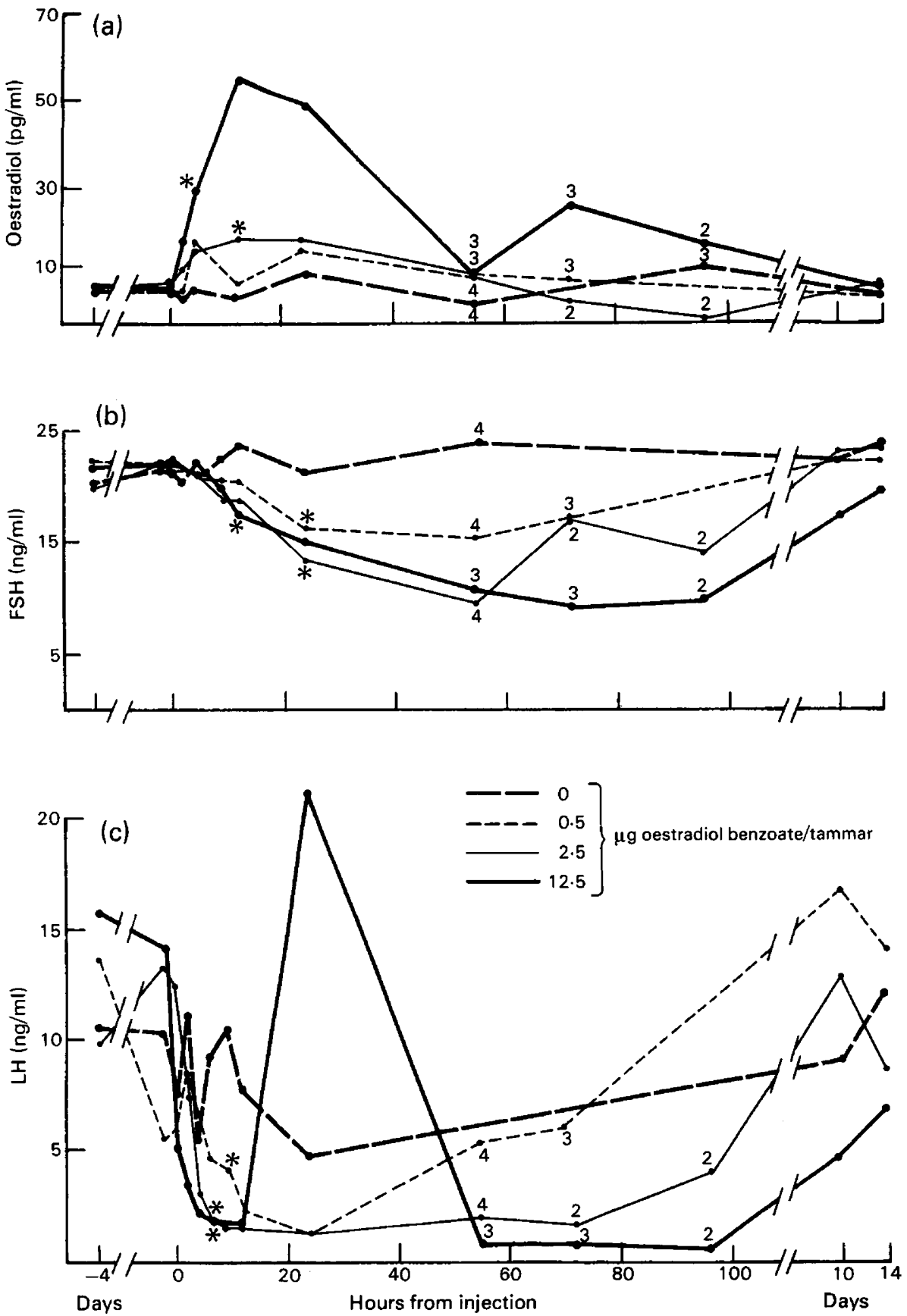

Text-fig. 1. Mean concentrations ( $\mathrm{N}=8$ ) of (a) oestradiol, (b) FSH, and (c) LH after injection of oestradiol benzoate to tammars in the non-breeding season (Exp. 1). When $\mathrm{N}<8$, numbers indicate sample size. ${ }^{*}$ Time of first significant $(P<0.01)$ depression from control levels of $\mathrm{LH}$ and FSH $(b, c)$ and increase from control levels of oestradiol (a).

increases, $8.8-13.5 \mathrm{pg} / \mathrm{ml}$, which became significantly $(P<0.01)$ higher compared with the control at $12 \mathrm{~h}$. The lowest dose did not elicit a significant increase in plasma oestradiol. By $48 \mathrm{~h}$ after injection oestradiol levels had returned to pretreatment values. 

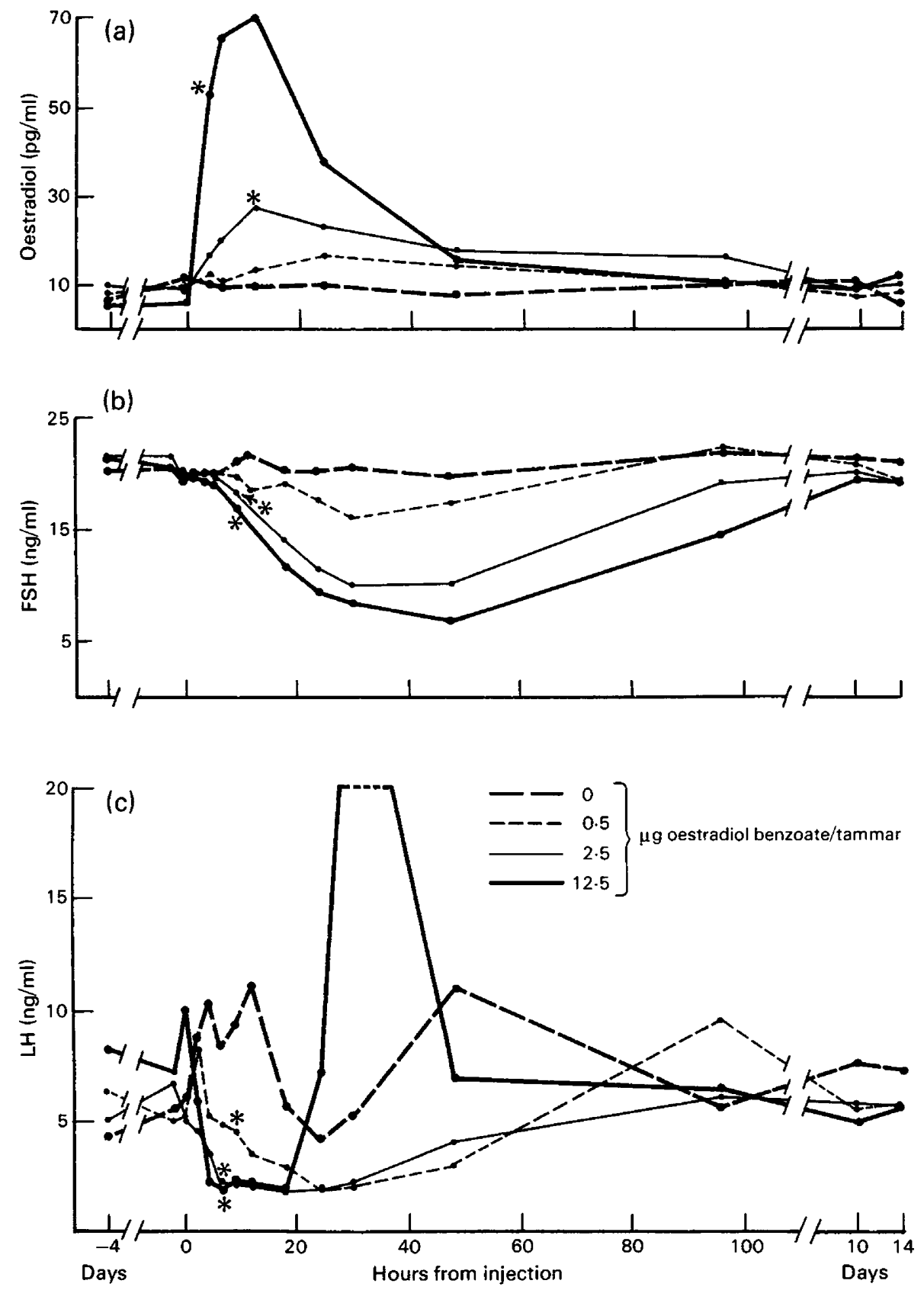

Text-fig. 2. Mean concentrations ( $N=8$ ) of (a) oestradiol, (b) FSH, and (c) LH after injection of oestradiol benzoate in the breeding season (Exp. 2). For FSH doses of 0.5 and $0 \cdot 1 \mu \mathrm{g}, \mathbf{N}=7$. *Time of first significant $(P<0.01)$ depression from control levels of FSH and LH (b, c) and increase from control levels of oestradiol (a).

\section{FSH}

The oestradiol injections resulted in a dose-dependent depression of FSH concentrations from the elevated values observed after ovariectomy. The differences between the control and the highest dose in both experiments became significant $(P<0.01)$ between 9 and $12 \mathrm{~h}$ with a gradual 
lowering of concentrations, to a minimum around $48 \mathrm{~h}$ (Table 1), followed by a slow recovery, with values at $96 \mathrm{~h}$ still significantly $(P<0.01)$ depressed. In Exp. 2 the intermediate dose produced significant $(P<0.01)$ depression from the control value between 9 and $48 \mathrm{~h}$ after injection, recovering by $96 \mathrm{~h}$, while in Exp. 1 this depression showed only at $24 \mathrm{~h}$. The lowest dose of oestradiol elicited significant depression only at $24 \mathrm{~h}$ in Exp. 1.

$L H$

LH concentrations also exhibited dose-dependent depression after injection of oestradiol. There was considerable variability in the response of LH secretion with respect to treatments. In both experiments significant differences from the control dose had appeared at $6 \mathrm{~h}$ with the highest and intermediate dose, and at $9 \mathrm{~h}$ with the lowest dose $(P<0 \cdot 01)$. In Exp. 1 these doses produced maximum depression down to similar values $(1.8 \mathrm{ng} / \mathrm{ml})$ at 6,12 and $24 \mathrm{~h}$ respectively after injection (Table 1). Similarly depressed LH values $(\sim 2 \cdot 0 \mathrm{ng} / \mathrm{ml}$ ) had occurred by 6,18 and $24 \mathrm{~h}$ in Exp. 2 and this depression continued for at least $48 \mathrm{~h}$ after injection with the two lower doses.

With the highest oestradiol dose, the initial period of depression was followed by a transient increase in $\mathrm{LH}$ which peaked at $24 \mathrm{~h}(21.2 \mathrm{ng} / \mathrm{ml})$ in Exp. 1 and $30 \mathrm{~h}(28.3 \mathrm{ng} / \mathrm{ml})$ in Exp. 2. The LH value at $24 \mathrm{~h}$ after injection in Exp. 2 was significantly less than that for Exp. 1. Peak LH values varied from 7.5 to $>50 \mathrm{ng} / \mathrm{ml}$.

\section{Discussion}

Results from both experiments establish clearly that, at all doses used, oestradiol depressed LH and FSH concentrations in peripheral plasma. Even with the lowest dose, which did not significantly affect the basal plasma oestradiol level, LH was depressed; the response of FSH was equivocal with only one point of significant depression in Exp. 1. Nevertheless, these results indicate that the tonic suppression of these hormones in intact females could be achieved by native oestradiol at levels of $<10 \mathrm{pg} / \mathrm{ml}$.

In both groups of animals the response to the highest dose of oestradiol gave an LH concentration in the peripheral circulation that was transiently raised to a level similar to that observed in intact females at oestrus (Flint \& Renfree, 1982; Shaw \& Renfree, 1984). The secondary rise in LH, induced within 12-18 h of this peak in oestradiol, was very similar in both magnitude and timing to the preovulatory LH surge in intact females. Oestrus in tammars occurs $8 \mathrm{~h}$ post partum and is followed 5-8 h later by an LH surge, of about $12 \mathrm{~h}$ duration, and ovulation within 24 h (Evans et al., 1980; Tyndale-Biscoe, Hinds, Horn \& Jenkin, 1983). The synchrony of oestrus and the LH surge may be due, therefore, to the positive feedback effect of increasing concentrations of oestradiol from the preovulatory follicle (Harder et al., 1984). No such response to the oestradiol benzoate dose was observed in FSH, which supports the conclusion that these two hormones respond differently.

The responses of the two groups of females to the same series of treatments were very similar. Small differences in time of response do not detract from the main conclusion that there is no seasonal change in the responsiveness of the hypothalamus-pituitary axis to oestradiol. Description of the positive-feedback response by LH is incomplete given the differences in sample times between the two experiments. This is in marked contrast to the different negative-feedback response of ovariectomized ewes in the breeding season and anoestrus to implanted oestradiol (Legan, Karsch \& Foster, 1977; Webster \& Haresign, 1983). However, Haresign \& Friman (1983) have demonstrated that the induced positive-feedback effect on LH does not display any seasonal variation.

The overall response of the gonadotrophins in the tammars after ovariectomy was also very similar at both times of the year (in contrast to the conclusion of Tyndale-Biscoe \& Hearn, 1981), a result analogous to that of ewes and red deer stags (Karsch, Legan, Hauger \& Foster, 1977; Lincoln 
\& Kay, 1979) and unlike that of the ram (Pelletier \& Ortavant, 1975) and animals of other species which show true anoestrus, such as snow-shoe hares and hamsters (Davis \& Meyer, 1973; Turek, Elliott, Alvis \& Menaker, 1975).

The results of this paper do not support the suggestion of Hearn et al. (1977) that the marked seasonality of the tammar is due, as it is in the sheep, to changing hypothalamic sensitivity to oestradiol negative feedback. Rather, they support the idea that seasonality is controlled by pituitary inhibition of the corpus luteum. This in turn may inhibit folliculogenesis and ovulation by low level secretion of oestradiol.

We thank Lyn Hinds, John Wright and Phillip Williamson for assistance in the collection of samples; Frank Knight for preparing the figures; and Dr C. H. Tyndale-Biscoe for help with the experiments and preparation of the manuscript.

\section{References}

Davis, G.J. \& Meyer, R.K. (1973) Seasonal variation of LH and FSH in bilaterally castrated snow-shoe hares. Gen comp. Endocr. 20, 61-68.

Evans, S.M. (1978) Pituitary-ovarian relationships in the tammar wallaby, Macropus eugenii (Desmarest). Ph.D. thesis, Australian National University.

Evans, S.M., Tyndale-Biscoe, C.H. \& Sutherland, R.L. (1980) Control of gonadotrophin secretion in the female tammar wallaby (Macropus eugenii). J. Endocr. 86, 13-23.

Flint, A.P.F. \& Renfree, M.B. (1982) Oestradiol-17 $\beta$ in the blood during seasonal reactivation of the diapausing blastocyst in a wild population of tammar wallabies. J. Endocr. 95, 293-300.

Harder, J.D., Hinds, L.A., Horn, C.A. \& Tyndale-Biscoe, C.H. (1984) Oestradiol in follicular fluid, uteroovarian venous and peripheral plasma during parturition and post-partum oestrus in the tammar wallaby (Macropus eugenii). J. Reprod. Fert. 72, 551-558.

Haresign, W. \& Friman, B.R. (1983) Response of ovariectomized ewes to injection of oestradiol-17 7 at different times of the year. J. Reprod. Fert. 69, 469472.

Hearn, J.P. (1974) The pituitary gland and implantation in the tammar wallaby, Macropus eugenii. J. Reprod. Fert. 39, 235-241.

Hearn, J.P., Short, R.V. \& Baird, D.T. (1977) Evolution of the luteotrophic control of the mammalian corpus luteum. In Reproduction and Evolution, pp. 255-264. Eds J. H. Calaby \& C. H. Tyndale-Biscoe. Australian Academy of Science, Canberra.

Hinds, L.A. \& Tyndale-Biscoe, C.H. (1982) Plasma progesterone levels in the pregnant and non-pregnant tammar, Macropus eugenii. J. Endocr. 93, 99-107.

John, J.A. \& Quenouille, M.H. (1977) Experiments: Design and Analysis, Ch. 11. Charles Griffin \& Co. Ltd, London.

Karsch, F.J., Legan, S.J., Hauger, R.L. \& Foster, D.L. (1977) Negative feedback action of progesterone on tonic luteinizing hormone secretion in the ewe: dependence on the ovaries. Endocrinology 101, 800806.

Legan, S. \& Karsch, F.J. (1980) Photoperiodic control of seasonal breeding in ewes: modulation of the negative feedback action of estradiol. Biol. Reprod. 23, 1061-1068.
Legan, S.J., Karsch, F.J. \& Foster, D.L. (1977) The endocrine control of seasonal reproductive function in the ewe: a marked change in response to the negative feedback action of oestradiol on luteinizing hormone secretion. Endocrinology 101, 818-824.

Lincoln, G.A. \& Kay, R.N.B. (1979) Effects of season on the secretion of $\mathrm{LH}$ and testosterone in intact and castrated red deer stags (Cervus elaphus). J. Reprod. Fert. 55, 75-80.

Pelletier, J. \& Ortavant, R. (1975) Photoperiodic control of LH release in the ram. I. Influence of increasing and decreasing light photoperiods. Acta endocr., Copenh. 78, 435-441.

Renfree, M.B., Green, S.W. \& Young, I.R. (1979) Growth of the corpus luteum and its progesterone content during pregnancy in the tammar wallaby, Macropus eugenii. J. Reprod. Fert. 57, 131-136.

Renfree, M.B., Wallace, G.I. \& Young, I.R. (1982) Effects of progesterone, oestradiol-17 $\beta$ and androstenedione on follicular growth after removal of the corpus luteum during lactational and seasonal quiescence in the tammar wallaby. J. Endocr. 92, 397403.

Renfree, M.B., Flint, A.P.F., Green, S.W. \& Heap, R.B. (1984) Ovarian steroid metabolism and oestrogens in the corpus luteum of the tammar wallaby. J. Endocr. 101, 231-240.

Shaw, G. \& Renfree, M.B. (1984) Oestradiol-17ß throughout pregnancy in the tammar, Macropus eugenii. $J$. Reprod. Fert. 72, 29-37.

Sutherland, R.L., Evans, S.M. \& Tyndale-Biscoe, C.H. (1980) Macropodid marsupial luteinising hormone: validation of assay procedures and changes in concentrations in plasma during the oestrous cycle in the female tammar wallaby (Macropus eugenii). $J$. Endocr. 86, 1-12.

Turek, F.W., Elliott, J.A., Alvis, J.D. \& Menaker, M. (1975) The interaction of castration and photoperiod in the regulation of hypophyseal and serum gonadotrophin levels in male golden hamsters. J. Endocr. 96, 854-860.

Tyndale-Biscoe, C.H. \& Hawkins, J. (1977) The corpora lutea of marsupials: aspects of function and control. In Reproduction and Evolution, pp. 245-252. Eds J. H. Calaby \& C. H. Tyndale-Biscoe. Australian Academy of Science, Canberra. 
Tyndale-Biscoe, C.H. \& Heam, J.P. (1981) Pituitary and ovarian factors associated with seasonal quiescence of the tammar wallaby, Macropus eugenii. J. Reprod. Fert. 63, 225-230.

Tyndale-Biscoe, C.H. \& Hinds, L.A. (1984) Seasonal patterns of circulating progesterone and prolactin and the response to bromocriptine in the female tammar, Macropus eugenii. Gen. comp. Endocr. 53, 5868.

Tyndale-Biscoe, C.H., Hearn, J.P. \& Reníree, M.B. (1974) Control of reproduction in macropodid marsupials. J. Endocr. 63, 589-614.
Tyndale-Biscoe, C.H., Hinds, L.A., Hom, C.A. \& Jenkin, G. (1983) Hormonal changes at oestrus, parturition and post-partum oestrus in the tammar wallaby (Macropus eugenii). J. Endocr. 96, 155-161.

Webster, G.M. \& Haresign, W. (1983) Seasonal changes in LH and prolactin concentrations in ewes of two breeds. J. Reprod. Fert. 67, 465-471.

Received 7 August 1984 